\title{
Considerações sobre o Plano de Marketing para as Microempresas Brasileiras
}

\section{Considerations on the Marketing Plan for Brazilian Micro Enterprises.}

\author{
Recebido: 27/04/2015 - Aprovado: 22/05/2015 - Publicado: 27/06/2015 \\ Edmir Kuazaqui ${ }^{1}$ \\ Doutor, mestre e graduado em Administração. P \\ Professor da ESPM - Escola Superior de Propaganda e Marketing \\ Coordenador e Professor de Pós-Graduação da UNIP - Universidade Paulista \\ ekuazaqui@uol.com.br
}

Processo de Avaliação: Double Blind Review

\begin{abstract}
Resumo: Este artigo tem o objetivo apresentar os principais conceitos de marketing aplicados pelas microempresas dentro de uma breve contextualização de um plano de marketing. O desenvolvimento e a evolução teórica partiram de pesquisa bibliográfica e da pesquisa de campo e observacional do autor do artigo. O objetivo não é esgotar o assunto nem tampouco construir um Plano de Marketing, mas, sim, de contribuir para a discussão, o aprendizado e a utilização do marketing mix no segmento das microempresas de forma mais assertiva. Concluiu-se que é inegável a importância das microempresas para qualquer país. Sua contribuição reside principalmente na inserção econômica e social. Deve-se frisar que as microempresas são as grandes responsáveis pela geração de empregos em nosso país, denotando seu destaque sob a óptica social e ecológica. Mais do que uma forma transitória de ganhar dinheiro, a realidade das microempresas deve ser analisada como um fenômeno econômico e social capaz de gerar crescimento regional e, consequentemente, global.
\end{abstract}

Palavras-Chaves: Microempresas, Marketing, Marketing Mix, Mercado Consumidor, Produto.

Abstract: This article aims to present the main marketing concepts applied by microenterprises within a brief contextualization of a marketing plan. The development and theoretical evolution have stemmed from the bibliographical research as well as field research and observational studies by the author of the article. The goal is neither to

\footnotetext{
${ }^{1}$ Autor para correspondência: Rua Doutor Álvaro Alvim, 123 - Vila Mariana, São Paulo - SP, Brasil - CEP: 04018010 .
} 
exhaust the topic or to construct a Marketing Plan, but rather to contribute to the discussion, learning and use of a marketing mix in the segment of micro-enterprises in a more assertive manner. It was concluded that there is no doubt as to the importance of micro-enterprises for any country. Their contribution lies mainly in the economic and social insertion. It should be taken into account that micro-enterprises are greatly responsible for job generation in our country, realising their prominent social and ecological perspective. More than a transient way of earning money, the reality of micro-enterprises must be considered as a social and economic phenomenon capable of generating regional and consequently, global growth.

Keywords: Micro-Businesses, Marketing, Marketing Mix, Consumer market, Product.

\section{INTRODUÇÃO}

Dentro da realidade contemporânea, as empresas oferecem importantes contribuições à sociedade. Sob o ponto de vista econômico, contribuem para a criação da renda e para o desenvolvimento que dela decorre. Sob o ponto de vista social, possibilitam, a partir do desenvolvimento econômico, a democratização de oportunidades e aprimoramento da população, que pode ter acesso a ensino e educação. Por fim, sob o ponto de vista empreendedor, a possibilidade de empreender, criar e inovar.

As microempresas possuem características e contribuições diferenciadas, em virtude de seu porte e dinâmica. Uma das grandes dificuldades desta categoria de empresa é melhor se inserir e se desenvolver no mercado em razão da limitação de receitas que influenciam no budget e na intensidade de marketing. Desta forma, a dinâmica de comunicação e as estratégias de marketing fazem-se diferenciadas em relação às empresas de médio e principalmente de grande porte.

Conforme Kraus, Harms e Fink (2010), é grande a contribuição dos pequenos negócios para a geração de novas ideias, produtos, serviços e negócios, uma vez que geralmente partem de uma visão mais empreendedora e com possibilidades de poder utilizar a criatividade e inovação de forma mais rápida.

Ferreira, Santos, Oliva e Gris (2008) atestam que o encerramento das atividades de uma microempresa não está associado a um fator específico, mas, de forma interligada, depende em grande parte da atuação direta do empreendedor. Conforme o GEOR - Gestão Estratégica Orientada para Resultados do Sebrae (2013), 24,9\% das empresas encerravam as suas atividades depois de dois anos de atividades. Uma das 
hipóteses levantadas pelo autor deste artigo, além das questões relacionadas ao porte e limitação de recursos, decorre da falta de conhecimentos gerenciais e ferramentas relacionadas à gestão do negócio.

Este artigo, então, procurará desenvolver os principais conceitos de marketing aplicados pelas microempresas dentro de uma breve contextualização de um plano de marketing. O desenvolvimento e a evolução teórica partiram de pesquisa bibliográfica e da pesquisa de campo e observacional do autor deste artigo.

Para analisar o nível de conhecimento das ferramentas e estratégias de marketing foi realizada uma pesquisa na Feira do Trianon, que é realizada aos domingos no calçadão da Avenida Paulista na cidade de São Paulo e tem um número médio de 160

expositores. É uma das mais tradicionais da região, onde sua origem remonta ao final da década de 1970, dai a escolha para estudo. Foi aplicado questionário devidamente tabulado e analisado, com questões abertas e fechadas, no sentido de levantamento dos conhecimentos administrativos, de outras informações correlacionadas dos expositores. Foi realizada outra pesquisa, onde a amostra é composta de microempresários de vários segmentos do município de São Paulo, totalizando 217 e que foram escolhidos por acessibilidade, pois "longe de qualquer procedimento estatístico, seleciona elementos pela facilidade de acesso a eles" (VERGARA, 2010, p. 47). Dos resultados, foram elaboradas as características de produto, precificação e distribuição, que compõem a análise da aplicação das ferramentas de marketing para as microempresas.

O objetivo não é esgotar o assunto nem tampouco construir um Plano de Marketing, mas contribuir para a discussão, o aprendizado e a utilização do marketing mix no segmento das microempresas de forma mais assertiva. Como base, pode servir como uma reflexão para estudos complementares, como por exemplo, focando na variável econômica, em especial relacionada ao cenário recessivo que o país está enfrentando desde 2014.

\section{O PLANO DE MARKETING E O MERCADO CONSUMIDOR}

Conforme Greatti (2004, p. 4), "O plano de negócio é uma linguagem que tem como função descrever de forma completa o que é ou o que pretende ser uma empresa”. Desta forma, nenhuma empresa pode sobreviver sem um bom plano de marketing. Isso significa dizer que todo empresário que deseja obter os melhores resultados deve ter 
claramente quais necessidades do mercado atenderá e como o fará. Também deverá compreender e assumir as responsabilidades da abertura e gestão de uma empresa. $\mathrm{O}$ fluxo financeiro que possibilitará o atendimento das necessidades da empresa e, ao mesmo tempo, garantirá o crescimento de forma sustentada, será, assim, obtido a partir da oferta de um pacote de benefícios reconhecidos.

Dentro desta perspectiva, o ponto de partida para o desenvolvimento de um plano estratégico é a limitação de suas competências a partir da criação da missão, visão, objetivos e valores corporativos. Depois, faz-se necessária a construção identificada de um marketing mix que possa atender, de forma pontual, as diferentes carências do mercado.

As microempresas, no Brasil, geralmente nascem a partir de diferentes situações. Uma das mais comuns é a perda de atividade remunerada, o que faz com que o profissional procure uma solução de curto e médio prazo para equilibrar o fluxo de caixa pessoal. Outra situação é quando ocorre o desdobramento de atividades que um profissional já exerce por meio de terceirização; outra ainda decorre do próprio perfil empreendedor, sendo normal o processo sucessório - de pai para filho, em pequenos negócios. Desta forma, é compreensível que empresas de pequeno porte não possuam claramente um planejamento estratégico mais elaborado, mas é inaceitável que se acomodem e trabalhem sem um bom plano de negócios e de marketing. Sem um bom plano de marketing, a empresa poderá até obter resultados, mas sem a certeza de resultados mensuráveis. Com ele, a empresa poderá obter resultados de forma mais organizada e passível de gerenciamento.

\subsection{O CONSUMIDOR COMO PRINCIPAL FOCO DA EMPRESA}

Todo negócio se inicia a partir do que o mercado pode oferecer em termos de oportunidades de negócios. Desta forma, toda organização deve ser criada a partir do atendimento das necessidades e desejos do mercado. O termo consumidor pode ser definido como todo aquele que pode comprar, alugar, utilizar ou usufruir de um produto ou serviço oferecido por uma empresa ou profissional. Conforme Foxxall (apud BAKER, 2005, p.87), “O processo decisório do consumidor é usualmente descrito como cognitivo. O consumidor se conscientiza de uma necessidade ou desejo e de um 
possível meio de satisfazê-lo, normalmente anunciado na propaganda de uma nova marca.".

De modo geral, como os consumidores estão pulverizados no mercado, uma das grandes dificuldades iniciais da microempresa é a limitação de seu grau de alcance. Empresas deste tipo costumam crescem a partir de demandas regionais, atendendo pontualmente a determinadas carências dos consumidores. E, como a oferta de produtos e serviços é feita por empresas de portes diferentes, as microempresas enfrentam dificuldades para facear os apelos de marketing que as médias e grandes empresas fazem ao consumidor. Hawkins, Mothersbaugh e Best (2007) ressaltam que este processo está intimamente relacionado ao atendimento da real necessidade do consumidor, bem como da percepção de valor atrelado a essa satisfação. Mesmo com todas as limitações, as microempresas devem estar atentas ao comportamento do consumidor, que pode ter uma grande mobilidade e contato com diferentes empresas de portes diferentes. Assim, uma das formas de sobrevivência dessas empresas é a utilização dos incentivos de longo e curto prazo, que será tratado mais adiante.

Um dos maiores desafios é que o consumidor faça sua primeira compra e depois a recompra, tornando-se, assim, cliente. Cliente é todo aquele que tem um vínculo, por vezes comercial, com uma empresa ou um profissional. Neste contexto, o marketing categoriza dois níveis de cliente:

- Cliente interno ou público interno, que se resume aos colaboradores da empresa. Neste sentido, estratégias de marketing como endomarketing servem como ações que visam ao envolvimento e comprometimento deste com os objetivos e metas da empresa.

- Cliente externo, que se caracteriza como aquele que vai adquirir o produto ou serviço. A empresa deve mensurar sua demanda de forma quantitativa e qualitativa. A primeira dará uma perspectiva de consumo e a segunda o perfil, que moldará as estratégias de marketing da empresa.

\subsection{A segmentação de mercado como principal estratégia para as microempresas}

Devido às suas particularidades, tais como limitação de recursos e alcance geográfico, recomenda-se que as microempresas utilizem, de forma pontual, as estratégias de segmentação de mercado. Sob o contexto do marketing, a técnica de 
segmentação de mercado considera de extremo valor as características do mercado onde a empresa deseja atuar. A segmentação de mercado preconiza a ideia de que o mercado é heterogêneo em relação às suas características e, consequentes necessidades, desejos e anseios. Desta forma, a técnica de segmentação exige a identificação e a mensuração das diferenças e as agrupa em categorias de consumo. Existem três formas de categorizar as estratégias de segmentação de mercado:

- A estratégia de marketing indiferenciado considera que o mercado é homogêneo em relação às suas características e necessidades. A empresa pode oferecer um marketing mix sem nenhuma diferenciação. Considerando a Teoria de Maslow, pode-se empregar esta estratégia para produtos e serviços que atendem às necessidades básicas, como água, por exemplo, e a prestação de serviços gerais;

- A estratégia de marketing concentrado considera que o mercado pode ter particularidades que a empresa pode atender. Desta forma, ela pode concentrar seus esforços em um único segmento de mercado. Neste caso, a regionalidade se antecipa como uma das principais variáveis, bem como particularidades e características de onde a empresa se encontra; e finalmente

- A estratégia de marketing diferenciado, em que a empresa identifica segmentos nos quais deseja atuar e desenvolve um marketing mix direcionado para cada um deles. Neste caso, a empresa tem um portfólio de estratégias para cada tipo de grupo de clientes. A seleção da melhor estratégia de segmentação implica:

- Por parte da empresa, permite a otimização de recursos econômicos, financeiros e humanos, envolvendo qualquer das estratégias citadas. Não havendo a diferenciação, existe a possibilidade de poder de barganha devido aos volumes transacionados. Se diferenciada, possibilita a aquisição de lotes compatíveis com a demanda.

- Por parte da demanda, existe a opção pelo produto ou serviço que melhor atenda a suas necessidades, podendo ocorrer então a fidelização e consequentemente a compra de lotes periódicos.

A segmentação de mercado decorre das necessidades das empresas de bem atenderem a seus clientes, o que faz dela uma forma sustentada de fidelização; de outro 
lado, se todas as empresas pensarem do mesmo modo, as mesmas estratégias se tornam formas de diferenciação competitiva. Baker (2005, p.44) afirma que a segmentação "[...] não somente é dinâmica e incerta, como também diversa: empresas são heterogêneas, assim como a natureza da demanda".

Pode-se afirmar categoricamente, portanto, que uma das principais técnicas de marketing que uma empresa pode aplicar e com a qual obterá retorno mais eficaz é a segmentação de mercado, pois:

- A empresa, com o conhecimento detalhado do mercado, pode entender melhor suas características, necessidades e carências. A partir da compreensão das características quantitativas e qualitativas históricas, é possível uma análise referencial de consumo;

- A partir da correta interpretação de dados e informações, a empresa deve formular o melhor marketing mix que vise a atender de forma pontual e sustentada o segmento que pretende atingir. Pela própria essência do sistema de marketing, o marketing mix é reflexo das características do potencial do mercado;

- De acordo com a demanda e oferta, possibilita e mensuração, otimização e gestão de recursos necessários para melhor atender o segmento, em razão das próprias necessidades da empresa;

- Permite flexibilizar as estratégias de acordo com as possíveis mudanças, mesmo que rápidas e sutis, deste e de outros nichos complementares.

A aplicação dos Sistemas de Informação - Sistemas de Informação em Marketing e Pesquisa de Mercado essencialmente - é primordial para a identificação dos nichos de mercado e respectivas características e necessidades que devam ser atendidas. A pesquisa de mercado identifica quantitativa e qualitativamente a demanda, referenciando o potencial de mercado. Por sua vez, os sistemas de informação em marketing possibilitam a retroalimentação de dados e informações a partir de dados secundários. A atualização desses dados e informações é importante para proporcionar à empresa os elementos básicos para a adequação das estratégias de marketing conforme o ciclo de vida do produto (CVP) ou serviço a ser analisado. Embora as microempresas 
tenham recursos limitados, entende-se que podem utilizar os sistemas de forma pontual, com a utilização de dados secundários a partir de fontes confiáveis.

A carteira de clientes de uma empresa pode ser categorizada de acordo com o perfil de consumo de seus clientes ativos:

- Carteira com clientes light users, que são aqueles que compram pequenos volumes, trazem grande custo operacional e contribuem individualmente pouco em relação às necessidades de capital de giro da empresa. Entretanto, podem garantir a manutenção do negócio, se agrupados devidamente. Uma pequena cafeteria pode ter um volume diário de receitas a partir da participação do famoso cafezinho;

- Carteira com clientes medium users, que compram periodicamente e em certo volume. Um restaurante por quilo pode diversificar seu cardápio periodicamente no sentido de fidelizar seus clientes; e

- Carteira com clientes heavy users, que compram grandes volumes, porém sem uma periodicidade. A empresa deve estar preparada para atender grandes lotes e consequentemente arcar com as despesas de estoque. Uma empresa de eventos pode aproveitar pequenas oportunidades de negócios, mas deve se concentrar em eventos específicos, como formaturas de cursos de graduação, que trazem semestralmente uma receita alta, o suficiente para atender às necessidades de capital de giro da empresa no ano inteiro.

Uma empresa, se adotar uma estratégia mista, deverá compatibilizar seus serviços no sentido de bem atender a todas as classes de clientes. Uma empresa de pequeno porte, por exemplo, deverá ter uma carteira diversificada de clientes com diferentes contribuições. Neste caso, deverá compatibilizar seus recursos e ter boas ferramentas de gestão e controle.

\section{O MARKETING MIX DAS MICROEMPRESAS}

A sobrevivência de uma empresa está diretamente relacionada ao aceite do que ela oferece ao mercado por parte do consumidor. McCarthy e Perreualt (1999, p.43) citam que o composto de marketing é o conjunto de "variáveis controláveis que a 
empresa reúne para satisfazer esse grupo-alvo" (consumidores). Essas variáveis controláveis, também conhecidas como marketing mix, podem ser categorizadas como os quatro p's: produto, preço, ponto de distribuição e promoção. A empresa, de forma geral, deve oferecer um mix que ofereça ao seu mercado soluções para as necessidades de seus consumidores. Por outro lado, o mercado deve retribuir a oferta de soluções por meio de pagamentos que garantam a sustentabilidade da empresa.

Também como variáveis controláveis, além do ambiente interno, há os fornecedores de matéria-prima e serviços, concorrentes e distribuidores, que serão analisados em conjunto com o marketing mix. Optou-se também por evitar a análise do macroambiente, que pode ser categorizado como variável incontrolável, como o ambiente econômico, tecnológico, demográfico, entre outros. Desta forma, mantém-se o foco no marketing mix. O primeiro a ser analisado será o produto.

\subsection{PRODUTO}

No marketing mix, é aquilo que é ofertado ao mercado de forma material. Kotler e Armstrong (2008, p.200), como base para todo o composto de marketing, definem

[...] um produto como algo que pode ser oferecido a um mercado para apreciação, aquisição, uso ou consumo e que pode satisfazer um desejo ou uma necessidade. Produtos incluem objetos físicos, serviços, eventos, pessoas, lugares, organizações, ideias ou um misto de todas essas entidades.

As microempresas possuem características e particularidades que influenciam o produto ofertado, conforme o Quadro 1: 
Quadro 1 - Características de produto.

\begin{tabular}{|l|l|l|}
\hline \multicolumn{1}{|c|}{ Item analisado } & \multicolumn{1}{|c|}{ Particularidade } & \multicolumn{1}{c|}{ Análise e recomendação } \\
\hline $\begin{array}{l}\text { Fornecedores de } \\
\text { matéria-prima e } \\
\text { serviços }\end{array}$ & $\begin{array}{l}\text { Por ter os recursos econômicos e } \\
\text { financeiros limitados, a empresa } \\
\text { pode ter dificuldade para } \\
\text { adquirir matéria-prima ou } \\
\text { serviços a preços competitivos. }\end{array}$ & $\begin{array}{l}\text { Pode-se optar pelas } \\
\text { cooperativas de compra, onde } \\
\text { matérias-primas iguais podem } \\
\text { ser adquiridas em volume, } \\
\text { aumentando o poder de } \\
\text { barganha junto aos } \\
\text { fornecedores. }\end{array}$ \\
\hline Produção & $\begin{array}{l}\text { A empresa pode ter dificuldade } \\
\text { para produzir ou simplesmente } \\
\text { vender em grandes quantidades. }\end{array}$ & $\begin{array}{l}\text { Pode tentar a terceirização de } \\
\text { processos e concentração na } \\
\text { sua carteira de clientes. }\end{array}$ \\
\hline Distribuidores & $\begin{array}{l}\text { A empresa geralmente } \\
\text { comercializa seus produtos de } \\
\text { forma regional, dentro de sua } \\
\text { capacidade de alcance. }\end{array}$ & $\begin{array}{l}\text { Pode tentar a negociação, } \\
\text { concentrando de forma } \\
\text { intensiva a distribuição do que } \\
\text { comercializa. }\end{array}$ \\
\hline Concorrentes & $\begin{array}{l}\text { A empresa pode ter diferentes } \\
\text { tipos de concorrência, de acordo } \\
\text { com as suas particularidades, } \\
\text { tais como porte e composição do } \\
\text { que comercializa. }\end{array}$ & $\begin{array}{l}\text { Deve ser elaborado um } \\
\text { monitoramento agressivo em } \\
\text { relação aos concorrentes } \\
\text { diretos e indiretos. }\end{array}$ \\
\hline
\end{tabular}

Fonte: Autor.

Desta forma, as microempresas deverão procurar alternativas, a fim de aumentarem as vendas por intermédio do aumento de sua capacidade de produção e, consequentemente, sua produtividade e economia de escala. Existem dois pontos cruciais para que consiga crescer de forma sustentada:

- Obter a produtividade e economia de escala significa dizer o aumento de seu retorno financeiro e diminuição de custos e despesas; e

- Obter diferenciações competitivas a partir de inovações graduais. Empresas de pequeno porte devem apresentar produtos ou serviços diferenciados ao mercado, apesar de suas limitações em pesquisa e desenvolvimento. As inovações oriundas de pequenas empresas podem representar uma forma de descentralizar o poder - naturalmente centrado nas grandes empresas.

Um bom exemplo de estratégia é o da planilha Excell, que faz parte do pacote do Windows. Anteriormente essa planilha de cálculo era conhecida como Lótus e a empresa que a desenvolveu não tinha condições de comercializá-la em nível internacional. Optou, então, pelo registro de patente e concessão para a Microsoft. 
Assim, o produto pôde ser comercializado globalmente, independente do porte e recursos da empresa em questão.

Uma solução à falta de recursos a ser adotada pela microempresa é valer-se da oferta de recursos financeiros por parte de entidades como o Banco Nacional de Desenvolvimento Econômico e Social, BNDES, bem como da orientação de entidades como o Serviço Brasileiro de Apoio às Micro e Pequenas Empresas, SEBRAE. Além disso, as instituições de ensino superior, por meio de suas empresas juniores e incubadoras, podem se constituir em caminhos para obtenção de inovação de produtos e serviços, e para a própria gestão do negócio.

A seguir, serão analisados os canais de distribuição numa ótica mais orgânica.

\subsection{CANAIS DE RELACIONAMENTO}

Na perspectiva do marketing mix, estão também os canais de distribuição, que inicialmente podem ser definidos como as entidades que propiciam a troca entre fabricantes e consumidores. Entretanto, numa visão mais orgânica, essas entidades desempenham diferentes e importantes papéis no processo de troca.

Conforme Kotler e Armstrong (2008, p.304), gerar um produto ou serviço e disponibilizá-los aos compradores requer a construção de relacionamentos não somente com os clientes, mas também com fornecedores e revendedores na cadeia de suprimento da empresa. Essa cadeia de suprimento consiste em parceiros "nos níveis acima" e "nos níveis abaixo".

No nível acima, estão os fornecedores e, no nível abaixo, o canal de distribuição, representado pelos atacadistas e varejistas. De acordo com o número de participantes, existem os seguintes níveis de canal:

Nível zero - caracterizado pela comercialização direta com o cliente. Neste caso, a empresa pode obter melhor retorno financeiro por não ter despesas de distribuição e comercialização, mas deverá absorver os custos operacionais e de transação;

Nível um - há a presença de varejistas, que podem ser definidos como organizações especializadas nas transações de troca e que incrementam o alcance da empresa junto ao mercado consumidor; e 
Nível dois - há a presença de atacadistas, que compram em volume e revendem aos varejistas e/ou clientes finais. Geralmente, há pouca possibilidade de atuação das microempresas neste nível, em razão da limitação de produção, com exceção de negociações e contratos específicos.

Enfim, toda empresa precisa ter uma visão integrada dos participantes de seu negócio, bem como o que cada entidade agrega em relação ao valor percebido pelo seu consumidor.

Quadro 2 - Características de distribuição.

\begin{tabular}{|c|c|c|}
\hline Item analisado & Particularidade & Análise e recomendação \\
\hline $\begin{array}{l}\text { Volumes } \\
\text { transacionados. }\end{array}$ & $\begin{array}{l}\text { A empresa não tem poder de } \\
\text { barganha junto ao canal de } \\
\text { distribuição. }\end{array}$ & $\begin{array}{l}\text { A empresa poderá optar por uma } \\
\text { negociação que propicie uma frequência } \\
\text { mais efetiva em detrimento do aumento } \\
\text { do custo e de despesa de distribuição e } \\
\text { de comercialização. }\end{array}$ \\
\hline Logística. & $\begin{array}{l}\text { A empresa } \text { pode ter } \\
\text { dificuldades no recebimento, } \\
\text { no estoque } \text { e na } \\
\text { comercialização do produto. }\end{array}$ & $\begin{array}{l}\text { Deverá ter uma gestão que possibilite } \\
\text { um planejamento racional a partir de } \\
\text { suas limitações. }\end{array}$ \\
\hline
\end{tabular}

Fonte: Autor.

As estratégias de distribuição podem ser categorizadas em intensiva, seletiva e exclusiva:

- As estratégias de distribuição intensiva implicam capacidade de distribuição forte em todo o mercado e com grande alcance geográfico. Pelas suas limitações, as microempresas não conseguem este nível de intensidade;

- As estratégias de distribuição seletiva indicam que a empresa pode optar por determinados revendedores, de acordo com as suas limitações de produção, bem como o acesso a diferentes categorias de consumidores; e

- As estratégias de distribuição exclusiva indicam que o microempresário optou por uma categoria de empresa para a comercialização de sua produção, o que lhe proporciona melhor controle e foco de suas vendas.

Empresas na área de alimentação, como, por exemplo, as pizzarias contornam as limitações geográficas por meio da terceirização de suas entregas. Outro fator 
importante é a possibilidade de dispersão geográfica. Um bom exemplo é o do Girafa's, que obteve crescimento considerável e está também presente internacionalmente.

Nos últimos tempos, as áreas de logística - interna e externa - e distribuição física se tornaram um dos maiores objetos de análise. De nada vale ter um bom produto se ele não for passível de distribuição ou se houver atraso na entrega. A solução para as microempresas é uma boa gestão a partir da criação de indicadores. Se por um lado a introdução de indicadores de gestão, como o Balanced Score Card (BSC) pode, num momento inicial, gerar barreiras, em virtude da padronização de procedimentos e processos, possibilitará à empresa ter uma visão mais completa do negócio e também dos canais de relacionamento. A seguir, as estratégias de precificação de produtos tangíveis.

\subsection{CONCEITOS INICIAIS DE PRECIFICAÇÃO}

Toda empresa deverá cobrar por aquilo que oferece ao mercado; todo consumidor deverá pagar e entender que está recebendo algo de determinado valor.

Assim, Kotler e Armstrong (2008, p. 258) observam que no sentido mais estrito, preço é a quantia que se cobra por um produto ou serviço. De maneira mais ampla, preço é a soma de todos os valores que os consumidores trocam pelos benefícios de obter ou utilizar um produto ou serviço. Historicamente, o preço tem sido o principal fator que afeta a escolha do comprador.

A formação do preço ao consumidor final é uma das mais difíceis decisões do composto de marketing, uma vez que envolve diferentes variáveis que, por vezes, não são de conhecimento do microempresário. Ela pode e deve envolver aspectos relacionados a custos de produção e comercialização, fixos e variáveis, e margem de lucro, ou seja, deve estar contextualizada com toda a cadeia de valores da empresa e objetivos corporativos. Complementando com McCarthy e Perreualt (1999, p.275): “os objetivos de preço devem fluir e estarem ajustados à empresa e a seus objetivos de marketing. Devem ser explicitamente declarados porque têm efeito direto sobre as políticas de preço, bem como os métodos usados em sua determinação."

De acordo com o planejamento estratégico de uma empresa, as estratégias de preço podem ser: 
- Elite ou desnatamento, em que a empresa oferece ao mercado um produto ou serviço a um preço elevado, entendendo que este tem alto valor agregado, e que existe um mercado consumidor interessado e com renda suficiente; e

- Piso ou de introdução, em que a empresa oferece ao mercado algo a um preço baixo, entendendo que o produto ou serviço não tem atributos suficientes que levem o consumidor a pagar um valor mais elevado por ele.

A seleção das estratégias de preço decorre de várias situações, envolvendo as categorias de produtos e serviços ofertados, concorrência, fornecedores, nível de concorrência e expectativa de retorno do investimento inicial e capital de giro. $\mathrm{Na}$ maioria dos casos, as microempresas oferecem um produto ou serviços a um nível competitivo, preocupadas principalmente com um retorno de curto prazo.

A seguir e encerrando a análise do mix, as diferentes formas de comunicação, informação e promoção de seus negócios, empresas, produtos e serviços.

\subsection{Ferramentas de promoção para a microempresa}

Para informar e comercializar seus produtos e serviços, todas as empresas devem utilizar um composto de promoção. Conforme Kotler e Armstrong (2008, p.357), a criação de bons relacionamentos com o cliente exige mais do que apenas desenvolver um bom produto, atribuir-lhe um preço competitivo e colocá-lo à disposição dos clientes-alvo. As empresas também precisam comunicar suas proposições de valor aos clientes.

O composto de promoção é formado por incentivos de longo e curto prazo, a fim de motivar o consumidor a comprar produtos e serviços no momento, mas também objetivam gerir o início e promover a manutenção dos relacionamentos comerciais. Os incentivos de longo prazo podem ser a propaganda e as relações públicas; e os incentivos de curto prazo podem ser categorizados como promoção de vendas e venda pessoal. 
Quadro 3 - Características e aplicações do composto de promoção.

\begin{tabular}{|c|c|c|}
\hline Item do composto & Particularidade & Análise e recomendação \\
\hline Propaganda. & $\begin{array}{l}\text { Estimulo de longo prazo que } \\
\text { visa a informar e gerar } \\
\text { relacionamentos, principalmente } \\
\text { com o público-alvo. Geralmente } \\
\text { utiliza veículos de comunicação } \\
\text { impressa, eletrônica e virtual. }\end{array}$ & $\begin{array}{l}\text { Em virtude do custo e } \\
\text { amplitude, em geral, a } \\
\text { microempresa deixa de optar } \\
\text { por esta alternativa de } \\
\text { promoção ou mesmo a opção } \\
\text { por veículos mais } \\
\text { regionalizados, como jornais } \\
\text { de bairros e similares. }\end{array}$ \\
\hline Relações Públicas. & $\begin{array}{l}\text { Estímulo de longo prazo que } \\
\text { visa à } \\
\text { relacionamentos com diferentes } \\
\text { públicos, inclusive } 0 \text { o do } \\
\text { mercado-alvo. Tem } \\
\text { ferramentas o new e o } \\
\text { release. }\end{array}$ & $\begin{array}{l}\text { Em virtude da diversidade de } \\
\text { formas de gerar os estímulos, } \\
\text { pode ser uma importante } \\
\text { ferramenta de exposição junto } \\
\text { a públicos próximos da } \\
\text { empresa. }\end{array}$ \\
\hline Promoção de vendas. & $\begin{array}{l}\text { Estímulos de curto prazo, que } \\
\text { visam a transformar a ação em } \\
\text { venda, como descontos, pacotes } \\
\text { promocionais, entre outros. }\end{array}$ & $\begin{array}{l}\text { É um dos estímulos mais } \\
\text { indicados para as empresas de } \\
\text { pequeno porte, pela facilidade } \\
\text { e por não ter custos elevados } \\
\text { de desenvolvimento. }\end{array}$ \\
\hline Venda pessoal. & $\begin{array}{l}\text { Estimulo de curto prazo que visa } \\
\text { à contribuição da força de } \\
\text { vendas. }\end{array}$ & $\begin{array}{l}\text { É um dos estímulos mais } \\
\text { utilizados pelas empresas de } \\
\text { pequeno porte, pela própria } \\
\text { natureza de suas operações. }\end{array}$ \\
\hline
\end{tabular}

Fonte: Autor.

As microempresas devem combinar as diferentes ações, de acordo com suas metas e objetivos, bem como em concordância com a expectativa e respectivo orçamento. De forma geral, a empresa deve, assim, gerar estímulos de longo prazo, divulgando o seu nome e promovendo seus respectivos produtos e serviços. Além disso, deve promover estímulos de curto prazo para concretizar a venda e ter o consequente retorno de seus investimentos. No caso específico das microempresas, é natural a utilização maior dos incentivos de curto prazo pela própria necessidade de retorno financeiro.

Uma opção contemporânea é a utilização da internet para a divulgação da empresa, bem como para a comercialização e venda de seus produtos e serviços. Lodish, Morgan e Kallianpur (2002) lembram da importância e relevância da web nos negócios das empresas e destacam o marketing viral. 
Algumas empresas podem obter exposição gratuita, cedendo parte de seus produtos e serviços. É natural que restaurantes cedam cortesias em troca de exposição em jornais e revistas.

Complementando com pesquisa realizada e atualizada pelo autor em conjunto com Teresinha Covas Lisboa e Fernando Brasil da Silva (2011), observa-se em alguns segmentos de pequenos negócios na cidade de São Paulo, a existência de certo desconhecimento das ferramentas e estratégias de marketing conforme a tabela a seguir:

Tabela 1: Conhecimentos administrativos.

\begin{tabular}{l|l|l|l|l|l|l}
\hline INSTRUMENTO & CONHECEM & $\%$ & DESCONHECEM & $\%$ & TOTAL & $\%$ \\
\hline Fluxo de caixa & 35 & 48,61 & 37 & 51,39 & 72 & 100,00 \\
\hline Preço de venda & 56 & 77,77 & 16 & 22,23 & 72 & 100,00 \\
\hline Técnicas de vendas & 66 & 91,66 & 06 & 8,34 & 72 & 100,00 \\
\hline Contabilidade & 15 & 20,83 & 57 & 79,17 & 72 & 100,00 \\
\hline Marketing & 27 & 37,50 & 45 & 62,50 & 72 & 100,00 \\
\hline Jurídico & 18 & 25,00 & 54 & 75,00 & 72 & 100,00 \\
\hline & 217 & & 215 & \multicolumn{3}{|c}{}
\end{tabular}

Fonte: KUAZAQUI; LISBOA; SILVA, 2011, p.7.

Tais desconhecimentos por parte dos microempresários derivam de vários motivos, tendo como principal a falta de formação especifica em administração e marketing, bem como nas áreas especificas de gestão.

Concluindo a análise do marketing mix, as pequenas empresas deverão analisar seus recursos e possibilidades de expansão e crescimento a partir das características do mercado onde desejam atuar. A administração e gestão de recursos com uma visão integrada do mercado podem propiciar à empresa uma visão de futuro mais clara, possibilitando-lhe um planejamento estratégico mais forte e que garanta a sua sustentabilidade.

Concluindo o artigo, serão analisadas, brevemente, as tendências de marketing com foco na responsabilidade social e sustentabilidade.

\section{TENDÊNCIAS DE MARKETING PARA AS MICROEMPRESAS}


As microempresas contribuem de forma significativa para a economia nacional, mas são influenciadas pelas variáveis externas, tais como ambiente internacional, econômico, social, tecnológico, demográfico, geográfico, entre outros.

De acordo com o SEBRAE, tem crescido a quantidade de microempresas no país, o que denota também certo nível de empreendedorismo. Talvez fosse menor o número de novos pequenos negócios, se a decisão de abertura envolvesse somente os aspectos financeiros e tangíveis; mas o espírito empreendedor impulsiona o empresário a pensar diferente e agregar mais força ao seu negócio. Como consequências diretas, há a geração de postos de trabalho, que traduzem o ganho social direto, além da possibilidade da criação de novas tecnologias e inovação.

Oliveira (2008, p.3) afirma que o campo da responsabilidade social não trata somente de empresas multinacionais, que têm impacto global. Empresas pequenas têm uma atuação econômica importante em nível local em muitos lugares do mundo. Além disso, muitas têm uma relação muito próxima com a sociedade, investindo em projetos sociais, mesmo que não sejam reconhecidos como ações de responsabilidade social.

Em contraponto, Ghemawat (1999) desenvolve interessante teoria sobre a gestão a partir da utilização de recursos (sejam eles limitados ou não) para um crescimento sustentado. Finalmente, destaca-se, aqui, um texto do Guia Exame (2011, p.88), segundo o qual, em todo o mundo, a busca por uma economia mais sustentável transformou-se numa das grandes esperanças de retomada do crescimento. Novas tecnologias terão de ser criadas, métodos de produção terão de ser revistos e é possível que a forma com que lidamos com os recursos naturais passe por uma mudança radical. De onde a inovação brotará? Difícil dizer. Se o exemplo da revolução tecnológica se repetir, muito das novidades virão de empresas nascentes, geradas por empreendedores visionários. É isso, além de outros fatores, que vem unindo pequenas companhias com apelo sustentável e grandes negócios, interessados em melhorar seus próprios indicadores de desempenho nas áreas social e ambiental.

Desta forma, entende-se a importância atual das microempresas e sua significância num contexto mais amplo, visionário, dentro da ótica da responsabilidade social integrada e sustentabilidade ambiental.

\section{CONSIDERAÇÕES FINAIS}


É inegável a importância das microempresas para qualquer país. Sua contribuição reside principalmente na inserção econômica e social. Deve-se frisar que as microempresas são as grandes responsáveis pela geração de empregos em nosso país, denotando seu destaque sob a ótica social e ecológica. Mais do que uma forma transitória de ganhar dinheiro, a realidade das microempresas deve ser analisada como um fenômeno econômico e social capaz de gerar crescimento regional e, consequentemente, global. Como contribuições para futuros estudos, ampliar a amostra, de forma a aprofundar e focar a análise e resultados.

\section{REFERÊNCIAS}

BAKER, Michael J. Administração de marketing. $5^{\mathrm{a}}$ ed. São Paulo: Campus, 2005.

FERREIRA, Luis Fernando Filardi; SANTOS, Sílvio Aparecido dos; OLIVA, Fábio Lotti; GRIS, Celso Cláudio de Hildebrand. Fatores Associados à Mortalidade Precoce de Micro e Pequenas Empresas da Cidade de São Paulo. EnAnpad (2008). <http://www.anpad.org.br/admin/pdf/ESO-C727.pdf>. Acesso em 17 mai. 2015.

GHEMAWAT, Pankaj. A estratégia e os cenários dos negócios. Porto Alegre: Bookman, 1999.

GREATTI, Ligia. O Uso do Plano de Negócios como Instrumento de Análise Comparativa das Trajetórias de Sucesso e Fracasso Empresarial. <http://www.anpad.org.br/diversos/trabalhos/EnANPAD/enanpad_2004/ECE/2004_EC E2007.pdf>. Acesso em 21 abr. 2015.

GUIA EXAME 2011. Sustentabilidade. Novembro/2011.

HAWKINS, Del I.; MOTHERSBAUGH, David L.; BEST, Roger J. Comportamento do consumidor. Construindo a estratégia de marketing. 10ª ed. São Paulo: Campus, 2007.

KOTLER, Philip; ARMSTRONG, Gary. Princípios de marketing. 12 ed. São Paulo: Pearson, 2008.

KRAUS, Sascha; HARMS, Rainer; FINK, Mathias; Enterpeneurial Marketing: Moving Beyond Marketing in New Ventures. International Journal of Entrepreneurship and Innovation Management. Vol. 11, n.1, 2010, pp. 19-34.

KUAZAQUI, Edmir; LISBOA, Teresinha Covas; SILVA, Fernando Brasil. A contribuição regional das feiras de artesanato na cidade de São Paulo. Rio de Janeiro. SEGET, 2011. 
LODISH, Leonard; MORGAN, Howard Lee; KALLIANPUR, Amy. Empreendedorismo e marketing. Lições do Curso de MBA da Wharton School. São Paulo: Campus, 2002.

McCARTHY, E. Jerome; PERREAULT Jr., William D. Marketing essencial. Uma abordagem gerencial e global. São Paulo: Atlas, 1999.

OLIVEIRA, José Antonio P. de. Empresas na sociedade. Sustentabilidade e responsabilidade social. São Paulo: Campus, 2008.

SEBRAE. Serviço Brasileiro de Apoio às Micro e Pequenas Empresas. Disponível em: <www.sebrae.gov.br.>. Acesso em: 13 Fev. 2012.

SEBRAE. GEOR - Gestão Estratégica Orientada para Resultados. Sobrevivência das empresas no Brasil. Coleção estudos e pesquisas. <http://www.sebrae.com.br/Sebrae/Portal\%20Sebrae/Anexos/Sobrevivencia_das_empre sas_no_Brasil=2013.pdf $>$. Acesso em 17 Mai. 2015.

VERGARA, Sylvia Constant. Projetos e relatórios de pesquisa em administração. 12.ed. São Paulo: Atlas, 2010.

VERGARA, Sylvia Constant. Métodos de pesquisa em administração. São Paulo: Atlas, 2005. 